\title{
Cellular Plasticity of Inflammatory Myeloid Cells in the Peritoneal Foreign Body Response
}

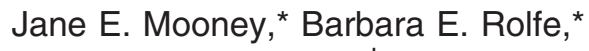 \\ Geoffrey W. Osborne, ${ }^{* \dagger}$ David P. Sester, ${ }^{\ddagger}$ \\ Nico van Rooijen, ${ }^{\S}$ Gordon R. Campbell, ${ }^{* \pi}$ \\ David A. Hume, ${ }^{\ddagger}$ and Julie H. Campbell ${ }^{*}$ \\ From the Centre for Research in Vascular Biology," \\ Australian Institute for Bioengineering and Nanotechnology, \\ the Queensland Brain Institute, ${ }^{\dagger}$ and the School of \\ Biomedical Sciences, "Iniversity of Queensland, St. Lucia, \\ Australia; The Roslin Institute and Royal (Dick) School of \\ Veterinary Studies, ${ }^{\ddagger}$ University of Edinburgh, Roslin, \\ Scotland, United Kingdom; and the Department of Molecular \\ Cell Biology, ${ }^{\S}$ Free University Medical Centre, Amsterdam, \\ The Netherlands
}

Implantation of sterile foreign objects in the peritoneal cavity of an animal initiates an inflammatory response and results in encapsulation of the objects by bone marrow-derived cells. Over time, a multilayered tissue capsule develops with abundant myofibroblasts embedded in extracellular matrix. The present study used the transgenic MacGreen mouse to characterize the time-dependent accumulation of monocyte subsets and neutrophilic granulocytes in the inflammatory infiltrate and within the tissue capsule by their differential expression of the $\operatorname{csf} 1 \boldsymbol{r}$-EGFP transgene, F4/80, and Ly6C. As the tissue capsule developed, enhanced green fluorescent protein-positive cells changed from rounded to spindle-shaped morphology and began to co-express the myofibroblast marker $\alpha$-smooth muscle actin. Expression increased with time: at day $14,11.13 \pm 0.67 \%$ of tissue capsule cells co-expressed these markers, compared with $50.77 \pm 12.85 \%$ of cells at day 28 . The importance of monocyte/macrophages in tissue capsule development was confirmed by clodronate-encapsulated liposome removal, which resulted in almost complete abrogation of capsule development. These results confirm the importance of monocyte/macrophages in the tissue response to sterile foreign objects implanted in the peritoneal cavity. In addition, the in vivo plasticity of peritoneal macrophages and their ability to transdifferentiate from a myeloid to mesen- chymal phenotype is demonstrated. (Am J Pathol 2010, 176:369-380; DOI: 10.2353/ajpath.2010.090545)

The tissue response to foreign materials including biomaterials and medical devices is known as the foreign body response and is universally characterized by inflammatory cell recruitment and subsequent encapsulation of the foreign material by fibrotic tissue. ${ }^{1}$ At the site of implantation an array of inflammatory mediators (and signaling molecules) including cytokines, growth factors, extracellular matrix proteins, and matrix-degrading enzymes create a dynamic microenvironment that mediates a defined sequence of events. ${ }^{2}$ In the initial acute inflammatory phase, neutrophils are recruited to the surface of the implanted materials, followed by lymphocyte and mononuclear cell involvement and foreign body giant cell formation (chronic inflammation). If the foreign material cannot be removed, resolution of these inflammatory responses occurs when a fibrous capsule has formed around it. ${ }^{3}$ Although the purpose of fibrous encapsulation is to isolate foreign material from the surrounding tissue, this fibrotic tissue, along with foreign body giant cells at the tissue/material interface, can significantly compromise the efficiency of medical devices or prostheses and frequently leads to device failure.

Our laboratory has observed a similar response to foreign material implanted in the peritoneal cavity. Within the first 3 to 5 days after implantation, the object is covered by rounded cells, many of which have a macrophage-like morphology and express the common leukocyte antigen Ly-5 (CD45). ${ }^{4}$ After 2 to 3 weeks, a tissue

\footnotetext{
Supported by grants from the Australian National Health and Medical Research Council, Australian Research Council, and Kidney Foundation (Bootle Grant). J.E.M. was supported by an Australian Postgraduate Award.

Accepted for publication September 10, 2009

Address reprint requests to Professor Julie H. Campbell, Ph.D., Centre for Research in Vascular Biology, Australian Institute for Bioengineering and Nanotechnology, University of Queensland, St. Lucia, 4072, QLD, Australia or Professor David A. Hume, Ph.D., The Roslin Institute and Royal (Dick) School of Veterinary Studies, University of Edinburgh, Roslin, EH25 9PS Scotland, UK. E-mail: julie.campbell@uq.edu.au or David.Hume@roslin. ed.ac.uk.
} 
capsule comprising multiple layers of myofibroblasts and extracellular matrix and covered by a continuous layer of mesothelial cells surrounds the object. ${ }^{5}$ In contrast with the tissue surrounding foreign material at other anatomical sites, the tissue encapsulating free-floating foreign objects in the peritoneal cavity is avascular. On harvest, the tissue has been used as an autologous graft for replacement/repair of hollow smooth muscle organs including blood vessels, bladder, vas deferens, and uterus. $^{5-7}$ Over the ensuing 2 to 3 months, the grafted tissue undergoes further cell differentiation and tissue remodeling to assume the morphology and function of the host organ. ${ }^{8}$

In addition to providing a sterile location to develop myofibroblast-rich tissue for engineering purposes, the peritoneal cavity is a convenient site to investigate the involvement of myeloid cells in the inflammatory response. The mononuclear phagocyte system encompasses bone marrow precursors, peripheral blood monocytes, tissue macrophages, and dendritic cells, all of which express the macrophage colony-stimulating factor receptor $(\mathrm{csf} 1 \mathrm{r}))^{9-11}$ Macrophages also express $\mathrm{F} 4 / 80^{12,13}$ and exhibit phenotypic and functional heterogeneity (reviewed in 14). Recently, blood monocytes have also been shown to exhibit heterogeneity in terms of expression of surface molecules such as Gr1 (Ly6C), chemokine receptors (CX3CR1), and migratory predisposition. ${ }^{15-17}$

Understanding the cellular processes involved in the foreign body response is central to the development of tissue engineering strategies using the resultant myofibroblast-rich tissue. It is also the key to maintaining the integrity and function of biomedical implants such as orthopedic implants, dental or breast implants, artificial organs, vascular grafts, heart valves, renal dialyzers, and controlled drug delivery systems. Thus, the aims of the current study were to characterize the cells involved in the inflammatory response to foreign objects implanted in the peritoneal cavity and to determine whether monocyte/ macrophages are the source of peritoneum-derived tissue capsule myofibroblasts. We have previously demonstrated that myofibroblasts within the tissue capsule are of bone marrow (hematopoietic) origin using sex-mismatched bone marrow transplant experiments. ${ }^{4}$ Others have demonstrated that labeled peripheral blood mononuclear cells, injected into the peritoneal cavity at the same time as foreign object implantation, contribute to tissue capsule formation. ${ }^{18}$ However, it is not clear whether monocyte/macrophages are a cellular source of tissue capsule myofibroblasts. Thus, we investigated the hypothesis that in the peritoneal foreign body response, monocyte/macrophages can transdifferentiate to myofibroblasts.

For these investigations we used the transgenic MacGreen mouse in which a promotor region of the c-fms (csf1r) proto-oncogene directs myeloid-specific expression of the reporter gene, enhanced green fluorescent protein (EGFP). ${ }^{19,20}$ The $c$-fms gene encodes the receptor for the cytokine CSF-1, which is essential for macrophage survival, proliferation, and differentiation. Our results demonstrate that the inflammatory myeloid cells recruited into the peritoneal cavity exhibit differential (bimodal) expression of csf1r-EGFP; when used in conjunction with markers F4/80 and Ly6C, the csf1r-EGFP reporter provides a unique marker of monocyte/macrophage subsets and neutrophilic granulocytes. We also show that monocyte/macrophages within the tissue capsule are capable of differentiating to a mesenchymal phenotype, evidenced by co-expression of myeloid (EGFP) and myofibroblast ( $\alpha$-smooth muscle [SM] actin) markers. These results provide evidence of the capacity for fully differentiated macrophages to transdifferentiate and suggest a greater potential for cellular plasticity than recognized previously.

\section{Materials and Methods}

\section{Mice}

Male and female c-fms-EGFP ("MacGreen") mice (in which a 7.2-kb promoter element of the c-fms gene, including the key enhancer, fms intronic regulatory element, directs specific expression of EGFP in macrophage, trophoblast, and granulocyte lineages) ${ }^{19,20}$ and wild-type (C57BL/6) control mice were purchased from the Transgenic Animal Service of Queensland and the University of Queensland Biological Resources, University of Queensland (St. Lucia, QLD, Australia). Mice were used at the age of 8 to 16 weeks in all experiments and maintained in our on-site animal facility according to institutional guidelines. All procedures were approved by the University of Queensland Animal Ethics Committee Guidelines and conform to the Animal Care and Protection Act Qld (2002) and the Australian Code of Practice for the Care and Use of Animals for Scientific Purposes (7th ed., 2004) published by the Australian National Health and Medical Research Council.

\section{Foreign Objects}

In this study, sterile cubes of boiled chicken egg white (approximately $0.125 \mathrm{~cm}^{3}$ ) were used as foreign objects. Egg white is composed predominantly of ovalbumin, an avian protein not found in mammals. Because it is acellular and almost 100\% protein, it can be easily removed during RNA isolation procedures. It can also be easily fixed and sectioned for histological analysis of the encapsulating fibrotic tissue.

\section{Surgical Procedure}

Mice were anesthetized by inhalation of isoflurane ( $2 \%$ in oxygen). Using sterile techniques, a 1-cm midline abdominal incision was made, and the foreign objects (4 cubes of boiled egg white) were inserted into the peritoneal cavity along with $1 \mathrm{ml}$ of sterile $0.9 \%$ sodium chloride (Baxter Healthcare, Sydney, Australia). The peritoneal wall was closed with 4-0 Vicryl (Ethicon, Johnson \& Johnson, Somerville, NJ), and the skin was sutured with 5-0 Sofsilk (Syneture, Mansfield, MA). In control animals surgery was performed as above, but implantation of the cubes of boiled egg white was omitted. 


\section{Macrophage Depletion}

Macrophage depletion was achieved using the "liposome-mediated macrophage suicide technique." ${ }^{21}$ Clodronate-encapsulated liposomes are taken up by phagocytosis; clodronate is then released into the cell by disruption of the phospholipid bilayers of the liposomes and induces apoptosis of the macrophage. ${ }^{22}$ To eliminate macrophages from the peritoneal cavity, mice received i.p. injections of $0.1 \mathrm{ml}$ of liposome-encapsulated clodronate 2 days before implantation of cubes of boiled egg white and then 2 and 4 days after the surgical procedure. This ensured depletion of both resident peritoneal macrophages and recently recruited macrophages either from the omentum or circulating blood monocytes. ${ }^{23}$ Clodronate was a gift from Roche (Mannheim, Germany) and incorporated into liposomes as previously described. ${ }^{21}$

\section{Animal Sacrifice and Isolation of Cells}

At various time points after implantation (days 2, 4, 7, 14, 21, and 28), mice were euthanized by carbon dioxide inhalation. The peritoneal cavity was lavaged by introduction of $10 \mathrm{ml}$ of ice-cold $\left(4^{\circ} \mathrm{C}\right)$ calcium- and magnesiumfree Dulbecco's PBS (Invitrogen, Eugene, OR). Peritoneal exudate cells were collected into 15-ml centrifuge tubes by puncturing the abdomen with an 18-gauge needle (Becton Dickinson, San Jose, CA). Cubes of boiled egg white and encapsulating tissue were removed and placed in PBS (Invitrogen) for further processing; only those that were free-floating and not attached to the serosal surface were harvested for further analysis.

\section{Collagenase Digestion of Tissue Capsule Cells}

Single cell suspensions of tissue capsules were obtained by enzymatic digestion in collagenase $(3.5 \mathrm{mg} / \mathrm{ml}$ in RPMI 1640, Worthington Biochemicals, Freehold, NJ) at $37^{\circ} \mathrm{C}$ for 1 hour. Cell suspensions were used for flow cytometric analysis.

\section{Flow Cytometry}

To enumerate recruitment of cells into the peritoneal cavity at various time points, absolute cell counts were determined using Flow-Count Fluorospheres (Beckman Coulter, Fullerton, CA) according to the manufacturer's guidelines and analyzed on an LSRII cytometer using Diva software (version 6.1.1, Becton Dickinson). For cell surface phenotyping, single-cell suspensions of peritoneal exudates or tissue capsules $\left(10^{6}\right.$ cells/tube) were washed once in calcium- and magnesium-free PBS containing $0.1 \%$ bovine serum albumin and $0.1 \%$ sodium azide (PBA, Sigma-Aldrich, St. Louis, MO), pelleted, and incubated with $5 \%$ rat serum (Sigma-Aldrich) in PBA for 30 minutes at $4{ }^{\circ} \mathrm{C}$. After washing, cells were incubated with rat anti-mouse CD16/CD32 (2.4G2, Mouse BD FC Block) for 15 minutes before staining with R-phycoerythrin-conjugated anti-F4/80 (clone A3-1, Serotec, Ra- leigh, NC), anti-CD45 (clone 30-F11), anti-Cd11b (clone M1/70), anti-Gr1 (Ly6G/C, clone Rb6-8C5), or anti-Ly6G (clone 1A8) (all obtained from BD Pharmingen, San Diego, CA) or with Alexa Fluor 647-conjugated Ly6C (clone ER-MP20, Serotec) for 30 minutes at $4^{\circ} \mathrm{C}$, followed by washing in PBA.

For intracellular staining, cells were fixed in $4 \%$ paraformaldehyde (Electron Microscopy Sciences, Hatfield, PA) for 10 minutes and permeabilized with $0.1 \%$ saponin (Sigma-Aldrich) for 5 minutes, followed by incubation in PBS containing 5\% donkey serum (Sigma-Aldrich) for 30 minutes at room temperature. Cells were then incubated with rabbit monoclonal antibody to $\alpha$-SM actin (Epitomics, Burlingame, CA) for 30 minutes at room temperature, followed by Cy5-conjugated donkey anti-rabbit IgG (Jackson ImmunoResearch Laboratories, West Grove, PA). Immunostaining with the relevant isotype controls was also performed to control for nonspecific binding. Cells were analyzed on an LSRII cytometer using Diva software.

For cell sorting, isolated tissue capsule cells were separated on the basis of size/granularity (forward/side scatter) and fluorescence intensity of EGFP, using FACSVantage SE Diva and Diva software (version 5.2), according to the manufacturer's standard configuration.

\section{Morphological Analysis with DIFF-Quik}

For differential staining of fluorescence-activated cell sorting (FACS)-separated tissue capsule cells, cytocentrifuged samples were stained with a DIFF-Quik stain set (Lab Aids, Narrabeen, NSW, Australia) according to the manufacturer's instructions and mounted in mount-quick (Daido Sangyo Co., Shinada, Japan). DIFF-Quik is a Romanowsky-type stain that provides rapid histological evaluation of peripheral blood and bone marrow smears. With this technique, monocytes and granulocytes are easily identified by their distinct nuclear and cytoplasmic staining. 24

\section{Embedding and Tissue Sectioning}

Tissue was OCT-embedded according to methods described previously. ${ }^{19}$ Frozen sections (10- $\mu$ m-thick) were cut using a Leica 3050 cryostat (Leica Instrument, Wetzlar, Germany) and collected directly onto SuperFrost Plus glass slides (Menzel-Glaser, Braunschweig, Germany). Slides were air-dried for 1 hour and then were processed for immunofluorescence analysis.

\section{Immunohistochemistry}

Nonspecific binding was blocked by incubation of tissue sections in blocking buffer (5\% goat serum; SigmaAldrich) and $1 \%$ bovine serum albumin (Sigma-Aldrich) in PBS for 1 hour at room temperature. Sections were then incubated with rabbit $\alpha$-SM actin monoclonal antibody overnight at $4^{\circ} \mathrm{C}$. Secondary staining was performed using an Alexa Fluor 594-conjugated goat anti-rabbit IgG (Invitrogen) with incubation for 1 hour at room tempera- 
ture. Sections were counterstained with the nuclear dye Hoechst 33342 (Invitrogen) and mounted in ProLong Gold antifade reagent (Invitrogen).

\section{Morphological Analysis of Tissue Capsules}

To visualize EGFP expression by cells within tissue capsules, frozen sections were counterstained with Hoechst 33342 and mounted in ProLong Gold antifade reagent.

\section{Statistical Analysis}

Data are presented as means \pm SD. PRISM software (GraphPad Software, Inc., San Diego, CA) was used to analyze differences between samples by one-way analysis of variance with Dunnett's multiple comparison test. For all experiments values of $P<0.01$ were considered significant.

\section{Results}

\section{Cell Recruitment to the Peritoneal Cavity After Sterile Foreign Object Implantation}

The implantation of foreign objects (sterile cubes of boiled egg white) in the peritoneal cavity of MacGreen and C57BL/6 (control) mice resulted in a significant increase in the number of cells within the cavity at all time points examined (days 2, 4, 7, 14, 21, and 28) compared with that in the normal ("unstimulated") peritoneal cavity $(P<0.01)$ (Figure 1). Cell numbers were maximal at day 7 , with $51.6 \pm 8.8 \times 10^{6}$ cells within the cavity at this time. The persistent inflammatory cell infiltrate occurred in response to the implanted foreign objects, because surgery alone elicited a short-lived inflammatory response, which had resolved by day 7; at this time point the peritoneal cavity of "surgery alone" controls contained $10 \pm$ $2.7 \times 10^{6}$ cells, not significantly different from the number in the unstimulated peritoneal cavity $(P>0.05)$.

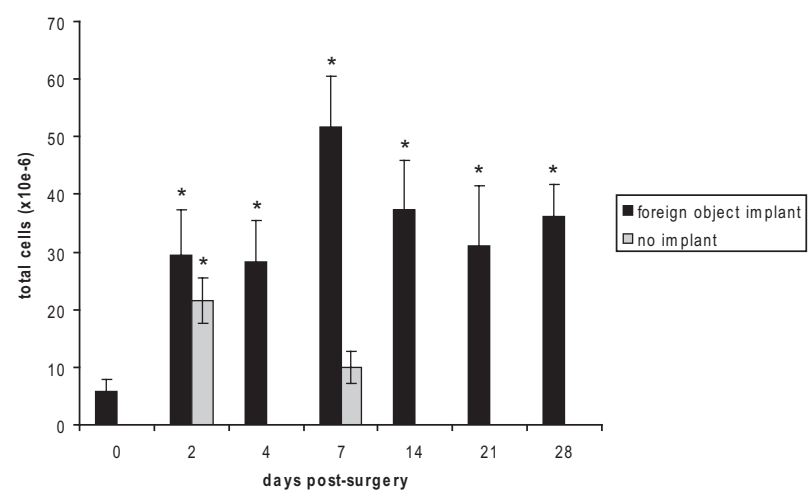

Figure 1. Cell recruitment to the peritoneal cavity after foreign object implantation. Histogram shows total cell numbers (mean \pm SD) in the peritoneal cavity before (day 0 ) and at various times after implantation of cubes of boiled egg white. Surgery alone (no implantation) elicited a transient inflammatory response, which was ameliorated by day $7 .{ }^{*} P<0.01$ compared with day 0 ( $n=9$ mice for each time point from three independent experiments).
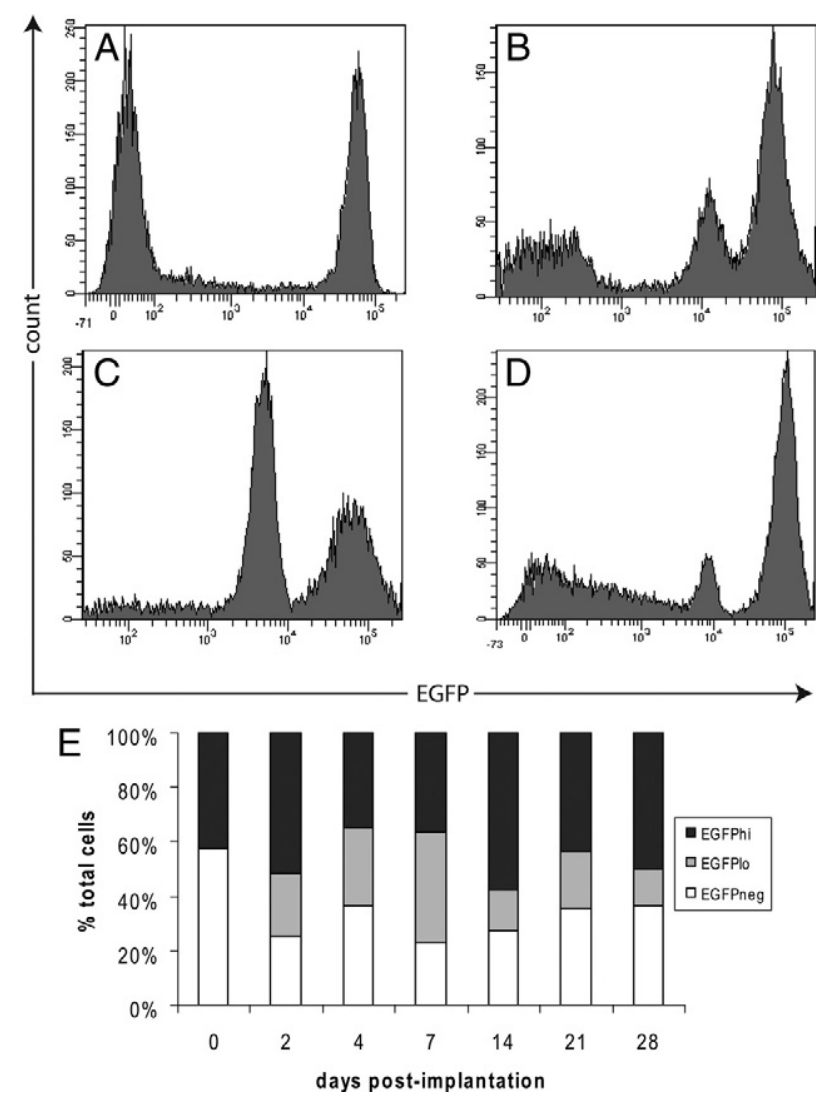

Figure 2. Myeloid cell recruitment to the peritoneal cavity after foreign object implantation. Representative FACS profiles showing EGFP expression by peritoneal exudate cells before (A) and at days $2(\mathbf{B}), 7(\mathbf{C})$, or 28 (D) after implantation of cubes of boiled egg white in the peritoneal cavity. E: Histogram shows the proportion of $\mathrm{EGFP}^{-}, \mathrm{EGFP}^{\mathrm{lo}}$, and $\mathrm{EGFP}^{\text {hi }}$ cells in the peritoneal cavity before and after implantation. The EGFP ${ }^{\text {lo }}$ subset was observed from day 2 onward. Results are expressed as the mean \% of total cells ( $n=9$ mice for each time point from three independent experiments).

\section{Myeloid Cell Recruitment to the Peritoneal Cavity After Sterile Foreign Object Implantation}

FACS analysis showed that within the unstimulated peritoneal cavity of MacGreen mice, there were two distinct populations of cells: EGFP-negative $\left(\mathrm{EGFP}^{-}\right)(57.6 \pm$ $5.6 \%)$ and EGFP-positive $\left(\right.$ EGFP $\left.^{+}\right)(42.4 \pm 5.6 \%)$ (Figure 2A). The EGFP ${ }^{+}$population was composed almost exclusively of cells expressing high levels of EGFP (EGFPhi). After implantation of foreign objects the proportion of EGFP $^{+}$cells within the peritoneal exudate increased markedly to $74.7 \pm 8.1 \%$ of total cells at day 2 after implantation (Figure 2B). The EGFP ${ }^{+}$population at this time point exhibited marked heterogeneity in EGFP expression levels and could be divided into two subpopulations, the EGFPhi population seen before implantation and a second population of low EGFP-expressing cells $\left(\right.$ EGFPlo $^{\circ}$ ). The proportion of the EGFPlo subset increased with time after implantation to a maximum at day 7 (Figure $2 \mathrm{C}$ ), comprising $52.3 \pm 7.4 \%$ of total EGFP ${ }^{+}$cells, coincident with maximal total cell numbers (shown in Figure 1); after this time, the proportion of EGFPlo cells decreased. At day 28 after implantation, EGFP ${ }^{+}$cells still contributed $63.7 \pm 4.8 \%$ of total cells within the peritoneal 

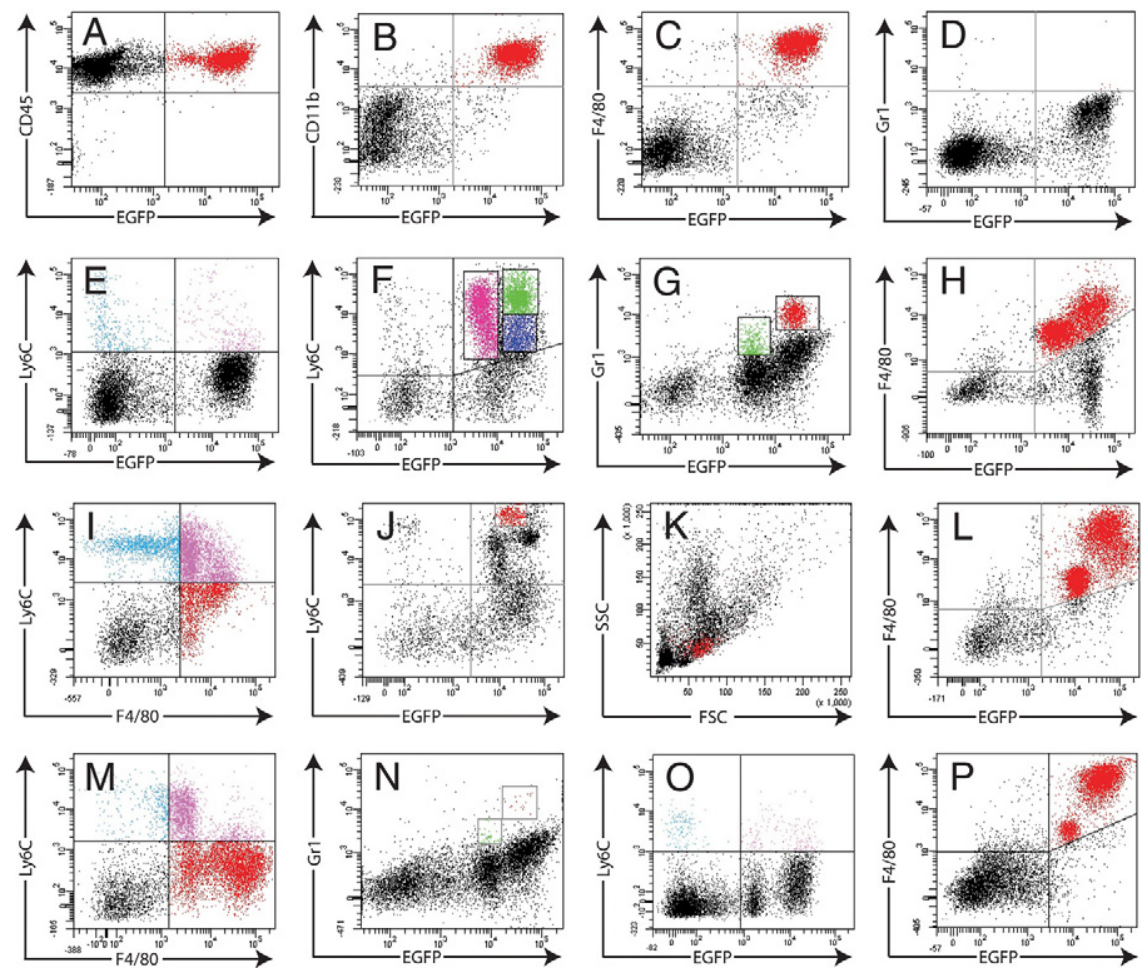

Figure 3. Characterization of the inflammatory infiltrate. Peritoneal exudate cells from the unstimulated peritoneal cavity stained with CD45 (A) CD11b (B) F4/80 (C), Gr1 (D), and Ly6C (E). After implantation of cubes of boiled egg white, an influx of $\mathrm{Ly}_{6 \mathrm{C}}^{+}(\mathbf{F}), \mathrm{Gr}^{+}(\mathbf{G})$, and $\mathrm{EGFP}^{\mathrm{lo}} \mathrm{F} 4 / 80^{+}$ (H) cells was observed at day 2. F: Three subsets of Ly6C-expressing cells observed at this time: EGFP $^{\mathrm{lo}}$ Ly6C ${ }^{\text {med-high }}$ (pink), EGFP ${ }^{\text {hi }}$ Ly6C ${ }^{\text {med }}$ (blue), and $\mathrm{EGFP}^{\mathrm{hi}}$ Ly $6 \mathrm{C}^{\text {hi }}$ (green). G: Two subsets of Gr1 ${ }^{+}$ cells: $\mathrm{EGFP}^{\text {hi }} \mathrm{Gr} 1^{\text {hi }}$ (red) and $\mathrm{EGFP}^{\mathrm{lo}} \mathrm{Gr}^{\mathrm{lo}}$ (green). Myeloid cells within the inflammatory infiltrate at day 2 were further characterized by costaining with F4/80 and Ly6C (I). An additional subset of Ly $^{+}$cells (red) was observed at day 4 (J) and exhibited physical features of inflammatory monocytes (K). At day 7 , peritoneal exudate cells showed up-regulation of F4/80 (L), with concomitant down-regulated expression of Ly6C $(\mathbf{M})$ and Gr1 (N). Inflammatory cell recruitment had ceased by day 14 with peritoneal exudate cells no longer expressing Ly6C $(\mathbf{O})$ and both subsets of EGFP ${ }^{+}$ cells expressing F4/80 (P). For all profiles, the forward scatter (FSC) and propidium iodide fluorescence was used to gate out debris and dead cells, respectively. In all panels, representative profiles are shown for $n=6$ mice per time point from two independent experiments. SSC, side scatter. exudate, the majority of which were of the EGFPhi subset (Figure 2D). The EGFP ${ }^{-}$subset was also observed at all time points after implantation, with proportions remaining relatively constant throughout, from $25.3 \pm 8.1 \%$ of total cells at day 2 to $36.4 \pm 6.8 \%$ at day 28 (Figure 2E).

\section{Characterization of the Peritoneal Inflammatory Cell Infiltrate}

To characterize the cells involved in the inflammatory response to foreign objects implanted in the peritoneal cavity, peritoneal exudate cells were analyzed before implantation and 2, 4, 7, 14, and 28 days after implantation by flow cytometry. At all time points examined, $>95 \%$ of total cells (both EGFP ${ }^{-}$and EGFP ${ }^{+}$) were leukocytes, identified by expression of CD45 (Figure 3A). The involvement of myeloid cells was then investigated using the markers CD11b and F4/80. Although CD11b is expressed by a number of cell types including monocyte/ macrophages, granulocytes, and lymphocytes, ${ }^{25,26}$ F4/80 is considered the most specific macrophage marker. ${ }^{12,13}$ Consistent with their identity as resident peritoneal macrophages, the majority of EGFP ${ }^{+}$cells within the unstimulated peritoneal cavity stained for both CD11b (myeloid cells) (Figure 3B) and F4/80 (macrophages) (Figure 3C). The $\mathrm{EGFP}^{-}$subset never expressed $\mathrm{F} 4 / 80$, whereas a small proportion of these cells did express CD11b and were most likely lymphocytes.

The myeloid differentiation antigen Gr1 (Ly6C/G) is expressed on granulocytes (neutrophils and eosinophils) and monocytes and has recently been used to define murine blood monocyte subsets. ${ }^{15}$ To gain further insight into the inflammatory cells recruited into the peritoneal cavity after foreign object implantation, we examined whether short-lived Gr1 (Ly6C/G) ${ }^{+}$blood monocyte subsets described by Geissmann et al ${ }^{15}$ were recruited to the peritoneal cavity after foreign object implantation and whether expression was restricted to either the EGFPhi or EGFPlo subset. Two different monoclonal antibodies were used in this study: clone RB6-8C5 that recognizes both Ly6C and Ly6G, ${ }^{27}$ and ER-MP20, which recognizes only the Ly6C antigen. As shown in Figure 3D, $\mathrm{Gr} 1^{+}$cells were not detected in the unstimulated peritoneal cavity, but a small proportion $(10.3 \pm 3.4 \%$ of total cells) of both the $\mathrm{EGFP}^{-}$and $\mathrm{EGFP}^{+}$fractions was shown to be $\mathrm{Ly} 6 \mathrm{C}^{+}$ (Figure 3E). At 2 days after implantation of foreign objects, an influx of EGFP ${ }^{+}$cells, which stained positive with either Ly6C or Gr1, was observed. Three subsets of Ly6C $^{+}$cells (EGFPlo Ly6C ${ }^{\text {med-high }}$, EGFPhiLy6C ${ }^{\text {med }}$, and EGFPhi Ly6C ${ }^{\text {hi }}$ ) (Figure 3F) and two subsets of $\mathrm{Gr}^{+}{ }^{+}$cells $\left(\right.$ EGFPh $^{\text {hi }} \mathrm{Gr}^{\text {hi }}$ and EGFPlo $\mathrm{Gr}^{\text {lo }}$ ) (Figure 3G) were identified. Surprisingly, at this time point the majority of EGFP ${ }^{+}$ cells in the inflamed peritoneal cavity expressed detectable F4/80, but levels were higher in the EGFPhi subset (Figure $3 \mathrm{H}$ ). A proportion of the EGFPhi subset did not express $F 4 / 80$, and these most likely represent granulocytes newly recruited to the peritoneal cavity. Further characterization of the different subsets was achieved by costaining with F4/80 and Ly6C (Figure 3I), with the newly recruited granulocytes represented in the upper left quadrant $\left(\mathrm{Ly}_{6 \mathrm{C}}{ }^{+} \mathrm{F} 4 / 80^{-}\right)$and mature macrophages in the lower right quadrant $\left(\mathrm{F} 4 / 80^{+} \mathrm{Ly}_{6 \mathrm{C}}{ }^{-}\right)$. In agreement with previous studies showing variable expression of F4/80 by monocyte subsets, ${ }^{17}$ immature monocyte/macrophages and granulocytes showed variable expression levels of both F4/80 and Ly6C (upper right quadrant). 


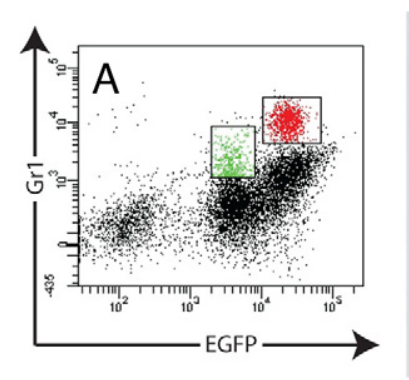

B

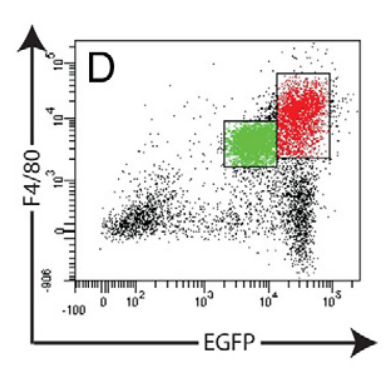

E
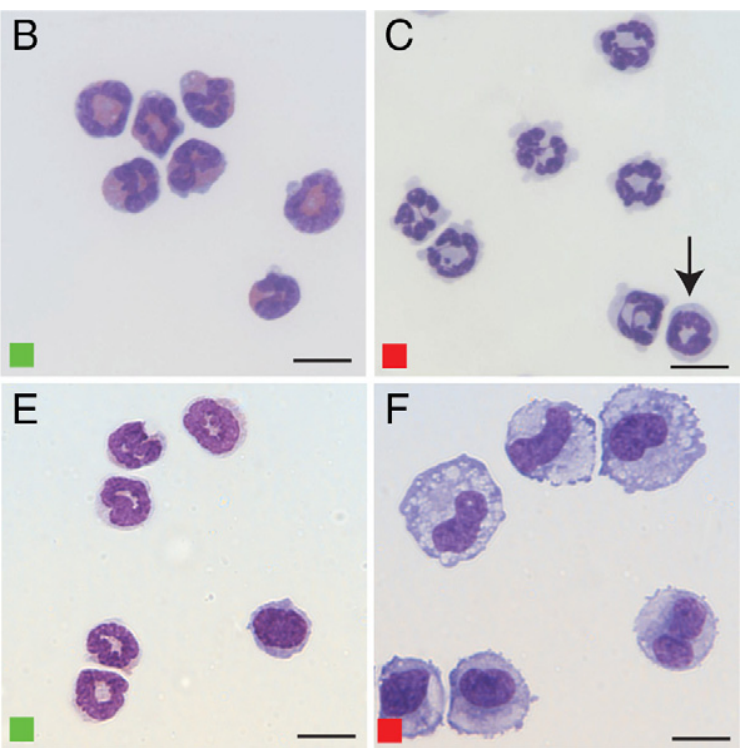

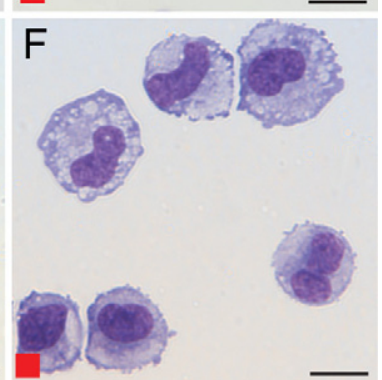

Figure 4. Morphological analysis of peritoneal lavage cells. Cells from the peritoneal cavity at day 2 after implantation stained for Gr1 (A) or F 4/80 (D) Morphological analysis (Diff-Quik) of FACS-sorted $\mathrm{EGFP}^{\mathrm{lo}} \mathrm{Gr}^{\text {lo }}$ (green) and EGFP ${ }^{\text {hi }} \mathrm{Gr}^{\text {hi }}{ }^{\text {hi }}$ (red) subsets shows neutrophils (B) and polymorphonuclear leukocytes and mononuclear cells with ringshaped nuclei (arrow) (C), respectively. FACSsorted $\mathrm{EGFP}^{\mathrm{lo}} \mathrm{F} 4 / 80^{\mathrm{lo}}$ cells were monocytes and neutrophils (E), whereas the EGFP ${ }^{\text {hi }} \mathrm{F} 4 / 80^{\mathrm{hi}}$ subset comprised macrophages $(\mathbf{F})$. Scale bars $=10 \mu \mathrm{m}$.
The cell populations in the peritoneal cavity changed rapidly. By day 4 , an additional $L y 6 C^{+}$subset was identified, characterized by intermediate expression of EGFP, very high Ly6C expression (Figure 3J), and low orthogonal (side) scatter (indicating mononuclearity) (Figure 3K). These cells would be considered the classic inflammatory monocyte, analogous to those attracted by stimuli such as thioglycollate broth. Concomitant with up-regulated expression of $\mathrm{F} 4 / 80$ at day 7 (Figure 3L), Ly6C (Figure 3M) and Gr1 (Figure 3N) were down-regulated on all subsets except a small population of EGFPlo cells. At this time $>95 \%$ of $\mathrm{EGFP}^{+}$cells expressed F4/80, providing evidence for a continuous maturation pathway of recruited monocytes and possibly granulocytes to macrophages. The inflammatory response had resolved by day 14 , evidenced by the absence of (newly recruited) $\mathrm{Ly} \mathrm{C}^{+}$cells in the peritoneal cavity (Figure 30). In addition, the Ly6C expression observed on the EGFPlo subset at day 7 was completely down-regulated. At this time all EGFP $^{+}$cells expressed F4/80 (Figure 3P). The FACS profiles for day 28 peritoneal cells (not shown) closely resembled those for day 14.

Because the Gr1 (Ly6C/G) antigen is commonly used to mark murine monocyte subsets and the current study identified two subsets of $\mathrm{Gr}^{+}$cells in the inflammatory infiltrate, we used this antibody to sort the cells and then confirm their identity based on morphology (Figure 4A). Diff-QUIK staining of the EGFPlo $\mathrm{Gr}^{\text {lo }}$ subset revealed that it was composed entirely of neutrophils, characterized by their pale-pink cytoplasmic staining (Figure 4B). The EGFPh $\mathrm{Gr}^{\text {hi }}{ }^{\text {hi }}$ subset was composed almost exclusively of polymorphonuclear-like ring cells (Figure 4C), with a small number of ring-shaped mononuclear cells, similar to those described by Biermann et al, ${ }^{28}$ also detected. These cells may represent the $\mathrm{Gr} 1^{+}$subset of inflammatory monocytes described by Geissmann et al. ${ }^{15}$

To investigate the observation that a proportion of the EGFPlo subset of peritoneal exudate cells expressed granulocyte-specific markers and exhibited morphological features of polymorphonuclear cells, but also ex- pressed the macrophage-specific marker F4/80, peritoneal lavage cells were FACS-sorted based on EGFP and F4/80 expression (Figure 4D). Morphological characterization of DIFF-Quik-stained cells confirmed that by day 2 inflammatory neutrophils express detectable F4/80 antigen, albeit at lower levels than mature macrophages. The EGFPlo F4/80 ${ }^{\text {lo }}$ subset contained neutrophils and monocytes (Figure 4E), whereas macrophages at different developmental stages comprised the EGFPhi $F 4 / 80^{\text {hi }}$ subset (Figure 4F). This result is in agreement with our previous demonstration that inflammatory neutrophils obtained 24 hours after peritoneal injection of thioglycollate broth can acquire F4/80 and other macrophage-specific gene expression in vitro in response to CSF-1.20 The unequivocal expression of $\mathrm{F} 4 / 80$ by neutrophils lends further support to the possibility that neutrophils can transdifferentiate to macrophages.

\section{EGFP-Positive Cell Involvement in the Developing Tissue Capsule}

Confocal microscopy of tissue capsule sections showed that at day 2 after implantation, the surfaces of implanted cubes of boiled egg white collected from MacGreen mice were covered by one to two layers of cells, most of which had a rounded appearance and expressed EGFP (Figure 5A). By day 14, the object was completely encapsulated by tissue, which was several cell layers thick, with the majority of cells still expressing EGFP (Figure 5B). At this time, $\mathrm{EGFP}^{+}$cells with both rounded and spindle-shaped morphologies were observed; rounded cells expressed high levels of EGFP aggregated in the innermost layers of the capsule, whereas the spindle-shaped cells were located toward the periphery. By day 28 , the capsule did not seem to have increased in thickness, and EGFP ${ }^{+}$ cells were still major contributors. Many spindleshaped cells were evident within the inner layers of the capsule, some of which still expressed EGFP (Figure 5C). Rounded cells expressing high levels of EGFP ${ }^{+}$ 


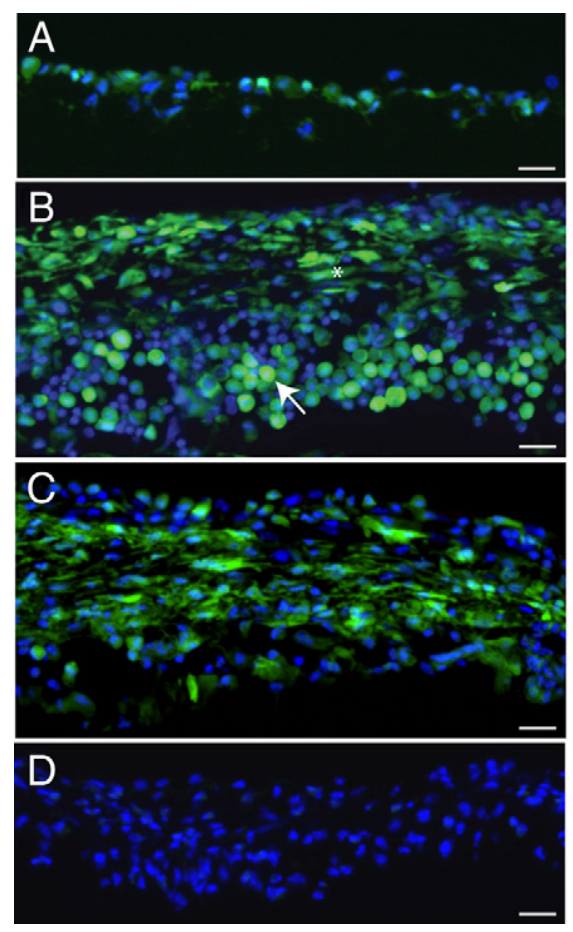

E
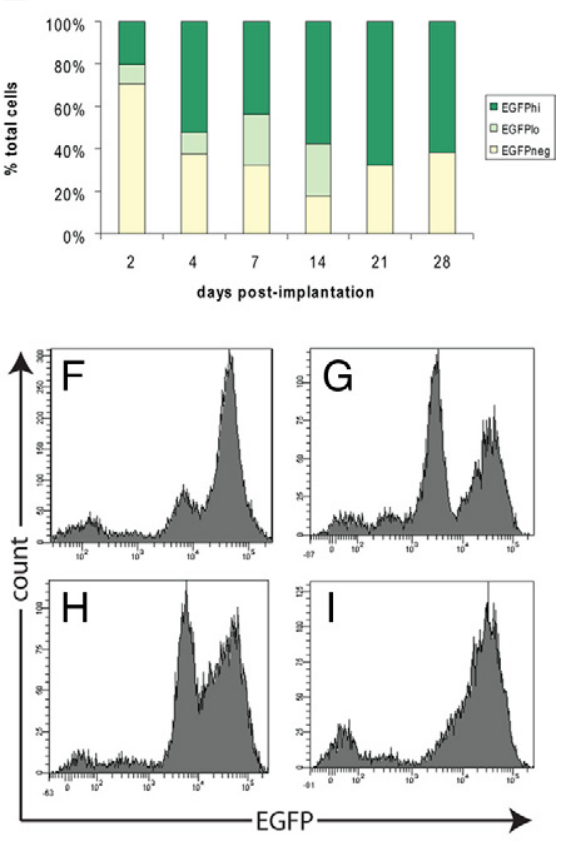

Figure 5. $\mathrm{EGFP}^{+}$cells contribute to tissue capsule development. EGFP (green) expression by cells within the developing tissue capsule in MacGreen mice at day 2 (A), day 14 (B), and day 28 (C) after implantation of sterile cubes of boiled egg white. D: Lack of EGFP expression in the day 14 tissue capsule from the C57/BL6 control; nuclei are counterstained with Hoechs 33342 (blue). Scale bars $=20 \mu \mathrm{m}$. E: Histogram shows the proportions of $\mathrm{EGFP}^{-}$, $\mathrm{EGFP}^{\mathrm{lo}}$, and EGFP $^{\text {hi }}$ cells within the capsule at the indicated time points. Representative FACS profiles of tissue capsule cells at day $2(\mathbf{F})$, day $7(\mathbf{G})$, day 14 (H), and day 28 (I). Results from $n=9$ mice from three independent experiments. were frequently observed on the surface of the tissue capsule, suggesting that monocyte/macrophages were still contributing to tissue capsule formation. Vascularization of the tissue capsule was never observed. EGFP expression was never detected in tissue capsules obtained from C57BL/6 control mice (Figure 5D). Furthermore, tissue capsule development was identical in wildtype and MacGreen mice, indicating that the csf1r-EGFP transgene had no effect on the cellular response to the implanted foreign objects.

FACS analysis of cells isolated from tissue capsules showed that the proportion of $\mathrm{EGFP}^{+}$cells in the tissue capsule increased from $27.6 \pm 7.4 \%$ of total cells at day 2 to $68.1 \pm 6.9 \%$ at day 7 and remained elevated through to day 28 when they constituted $61.9 \pm 10.6 \%$ of total cells (Figure 5E). EGFP ${ }^{-}$cells also contributed to tissue capsule development, and morphological analysis revealed that this subset comprised mainly mast cells and lymphocytes (data not shown). As observed for postimplantation peritoneal exudate cells, tissue capsule cells showed heterogeneity in EGFP expression levels, although the proportions of EGFPlo and EGFPhi cells varied and the distinctions between the two subsets was not clearly defined at the later stages of capsule development. At day 2, the majority of $\mathrm{EGFP}^{+}$cells were of the EGFPhi phenotype with the EGFPlo subset comprising $9.7 \pm 1.4 \%$ of total cells (Figure 5F). The distinction between the two subsets became clearly evident at day 7 with the EGFPlo and EGFPhi populations comprising $24 \pm$ 6.8 and $44 \pm 5.7 \%$ of total cells, respectively (Figure $5 \mathrm{G}$ ). From this time on the two subsets appeared to merge, with increasing EGFP expression possibly indicating differentiation/maturation of recruited monocytes and granulocytes (EGFPlo) to macrophages (EGFPhi) (Figure 5H). By day 28, the majority of cells were of the EGFPhi phe- notype and the two subsets could not be clearly separated (Figure 5l).

\section{Characterization of Tissue Capsule Cells}

To further characterize the cells involved in tissue capsule formation, single-cell suspensions were prepared from tissue capsules at days 2, 4, 7, 14, and 28 after implantation and expression of myeloid markers was analyzed by FACS. For all markers, tissue capsule cells displayed a pattern of expression similar to that observed for peritoneal exudate cells. At all time points, the majority of tissue capsule cells expressed CD45, with the exception of a small subset of EGFP ${ }^{-}$cells (Figure 6A). The majority of $\mathrm{EGFP}^{+}$cells also expressed the macrophage marker F4/80 (Figure 6B). As described for peritoneal exudate cells, monocyte-to-macrophage maturation was indicated by up-regulation of EGFP and F4/80 over time. At day $28, \mathrm{~F} / 80^{+}$macrophages still contributed $50 \pm$ $6.7 \%$ of total cells (Figure $6 \mathrm{C}$ ), confirming confocal microscope images showing $\mathrm{EGFP}^{+}$cells with macrophage-like morphology within the tissue capsule at this time point (Figure 5C).

Immunostaining with Gr1 and Ly6C antibodies identified an influx of $\mathrm{Ly}_{6} \mathrm{C}^{+}$(Figure 6D) and $\mathrm{Gr}^{+}$(Figure 6E) cells during early tissue capsule development, with maximal numbers at day 4 . By day 7 , there was an increase in the proportion of EGFPlo Ly6C $^{+}$cells, but as observed for peritoneal exudate cells the down-regulation of Ly6C expression by the EGFPhi subset had commenced (not shown). Ly6C (and Gr1) expression was down-regulated on all $\mathrm{EGFP}^{+}$subsets by day 14 (Figure 6F), and no further recruitment of $\mathrm{Ly} 6 \mathrm{C}^{+}$cells occurred after this time. Morphological analysis of FACS-sorted EGFP ${ }^{+}$sub- 

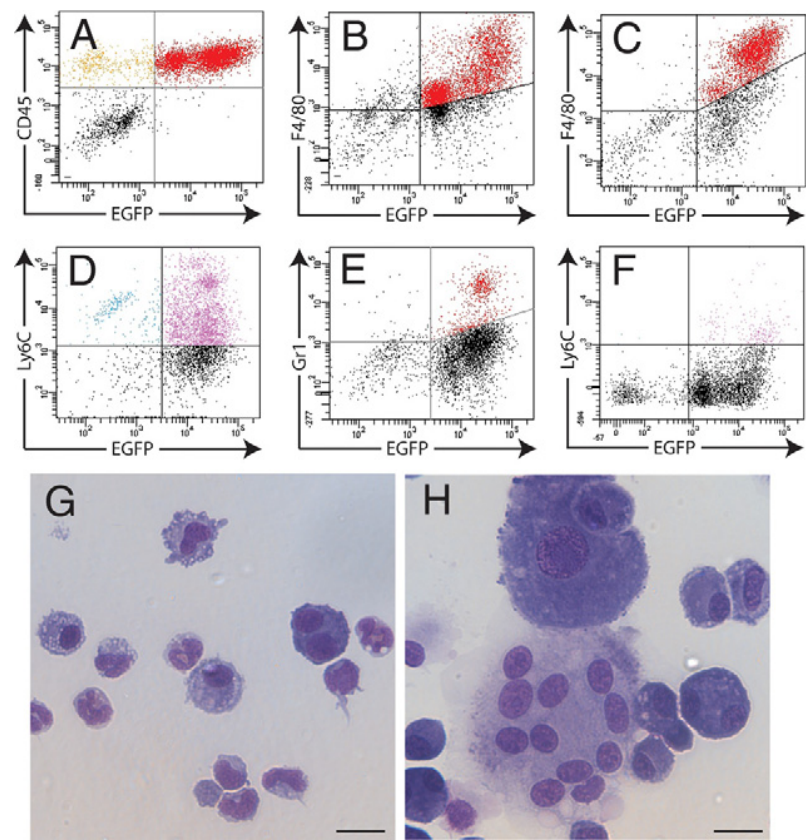

Figure 6. Characterization of tissue capsule cells. Dot plots from FACS analysis of cells from day 7 tissue capsules immunostained for CD 45 (A) or $\mathrm{F} 4 / 80$ (B) and from day 28 tissue capsules stained for F4/80 (C). Ly6C $^{+}$(D) and $\mathrm{Gr}^{+}(\mathbf{E})$ cells were involved in tissue capsule development and were maximal at day 4 but were reduced in number by day $14(\mathbf{F})$. Morphological analysis of the day $28 \mathrm{EGFP}^{\mathrm{lo}}$ and $\mathrm{EGFP}^{\text {hi }}$ subsets identified neutrophils and monocytes $(\mathbf{G})$ and macrophages and multinucleated giant cells $(\mathbf{H})$, respectively. Scale bars $=20 \mu \mathrm{m}$. FACS profiles are representative of $n=6$ mice for each time point from two independent experiments.

sets from the day 28 tissue capsule identified monocyte/ macrophages and neutrophils in the EGFPlo subset (Figure 6G) and macrophages, multinucleated giant cells, and other large cells, most likely myofibroblasts, within the EGFPhi fraction (Figure $6 \mathrm{H}$ ).

\section{Macrophages Are Essential for Tissue Capsule Development}

The abundance of macrophages within the tissue capsule at all time points led us to investigate the importance of these cells in capsule development. Depletion of both peritoneal macrophages and recently recruited blood monocytes with liposome-encapsulated clodronate was confirmed by FACS analysis of peritoneal lavage cells from clodronate-treated mice, which showed a marked reduction in total $\mathrm{EGFP}^{+}$cells compared with PBS liposomes or no-injection controls (data not shown). FACS analysis of tissue capsule cells at days 7 (Figure 7A) and 14 (Figure 7B) demonstrated a significant reduction in total $\mathrm{EGFP}^{+}$cells. At day 7, clodronate-encapsulated liposomes caused 35.8 and $76.8 \%$ reductions in the proportion of EGFPlo and EGFPhi cells, respectively. The effect was more pronounced at day 14, with almost complete ablation of both $\mathrm{EGFP}^{+}$subsets: a $73.3 \%$ reduction in the EGFPlo subset and a $97.9 \%$ reduction in the EGFP ${ }^{\text {hi }}$ subset. PBS liposome control injections (Figure 7C) did not cause a significant change in the EGFP expression profile of tissue capsules from MacGreen mice compared with the no-injection controls (Figure 7D).
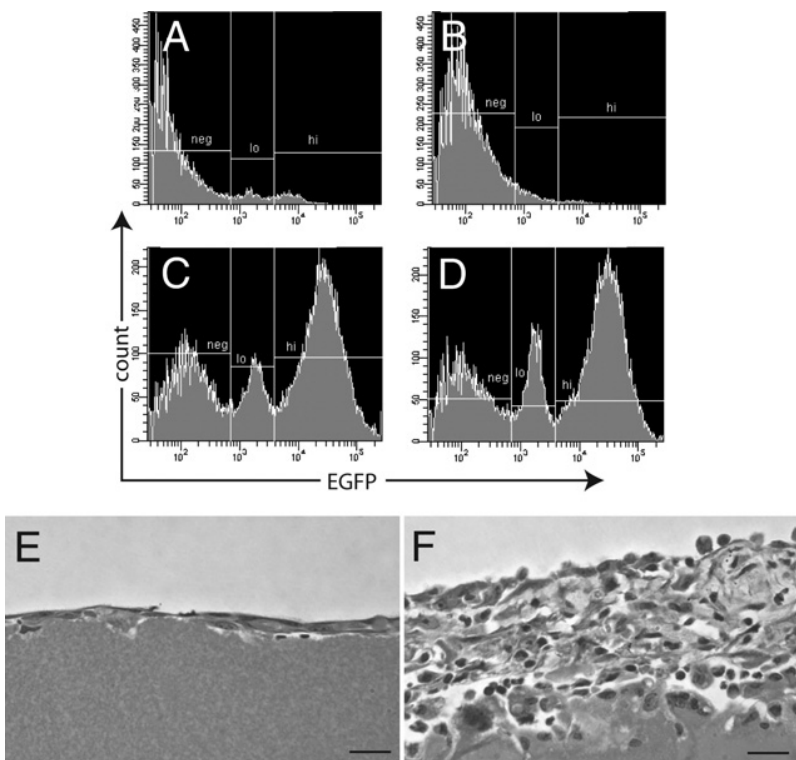

Figure 7. Macrophages are essential for tissue capsule development Histograms show reduction in total $\mathrm{EGFP}^{+}$cells in tissue capsules from clodronate-liposome-treated MacGreen mice at days 7 (A) and 14 (B) after implantation of sterile cubes of boiled egg white. Representative day 14 tissue capsule profiles show that PBS liposomes did not elicit a reduction in $\mathrm{EGFP}^{+}$cells within the tissue capsule (C) compared with the noinjection control (D). Representative images of tissue capsules from clodronate-liposome treated (E) and PBS control (F) MacGreen mice at day 14. Scale bars $=10 \mu \mathrm{m}$.

Histological analysis of tissue capsule sections showed a marked reduction in capsule development in clodronate-treated mice; at both days 7 and 14, the capsules consisted of only a monolayer of elongated mesothelial-like cells (Figure 7E). Conversely, in animals that received empty (PBS) liposomes, tissue capsule development resembled that in untreated mice. As shown in Figure 7F, the day 14 capsules from PBS liposometreated mice comprised multiple layers of rounded and spindle-shaped cells overlaid by a single layer of mesothelial-like cells. Taken together, these findings confirm the necessity for macrophages in tissue capsule development.

\section{Macrophage Transdifferentiation into Tissue Capsule Myofibroblasts}

Given the prevalence of macrophages within the tissue capsule through to day 28 , along with previous research showing the hematopoietic origin of capsular myofibroblasts, ${ }^{4}$ we sought to determine whether cells of myeloid origin (ie, monocyte/macrophages expressing EGFP) within the tissue capsule can transdifferentiate into $\alpha$-SM actin-expressing myofibroblasts. We reasoned that such cells would retain the stable EGFP protein even if transcription of macrophage-specific genes was extinguished. Flow cytometric analysis of cells isolated from tissue capsules showed that at day $14,12.7 \pm 0.5 \%$ of total cells expressed the myofibroblast marker $\alpha$-SM actin and nearly $85 \%$ of these co-expressed EGFP. At day 21 , $23 \pm 4.8 \%$ of cells expressed $\alpha$-SM actin, and at day 28 , $63 \pm 14.5 \%$ of total cells expressed $\alpha$-SM actin with 
A

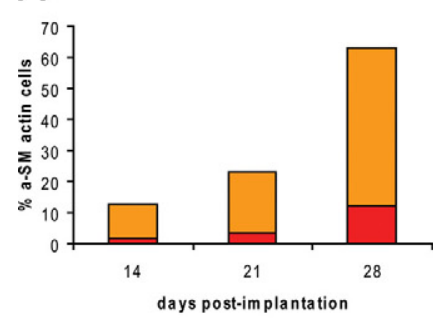

B

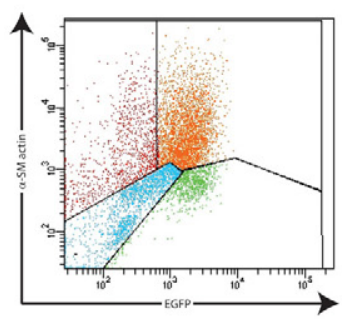

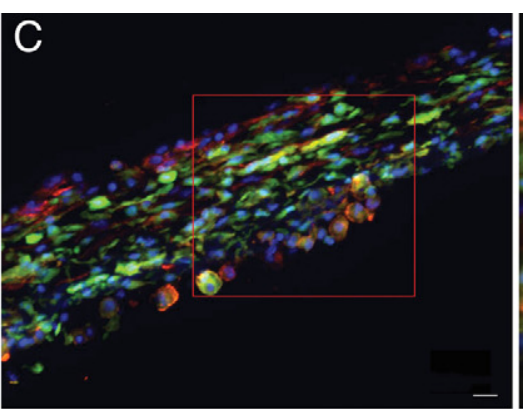
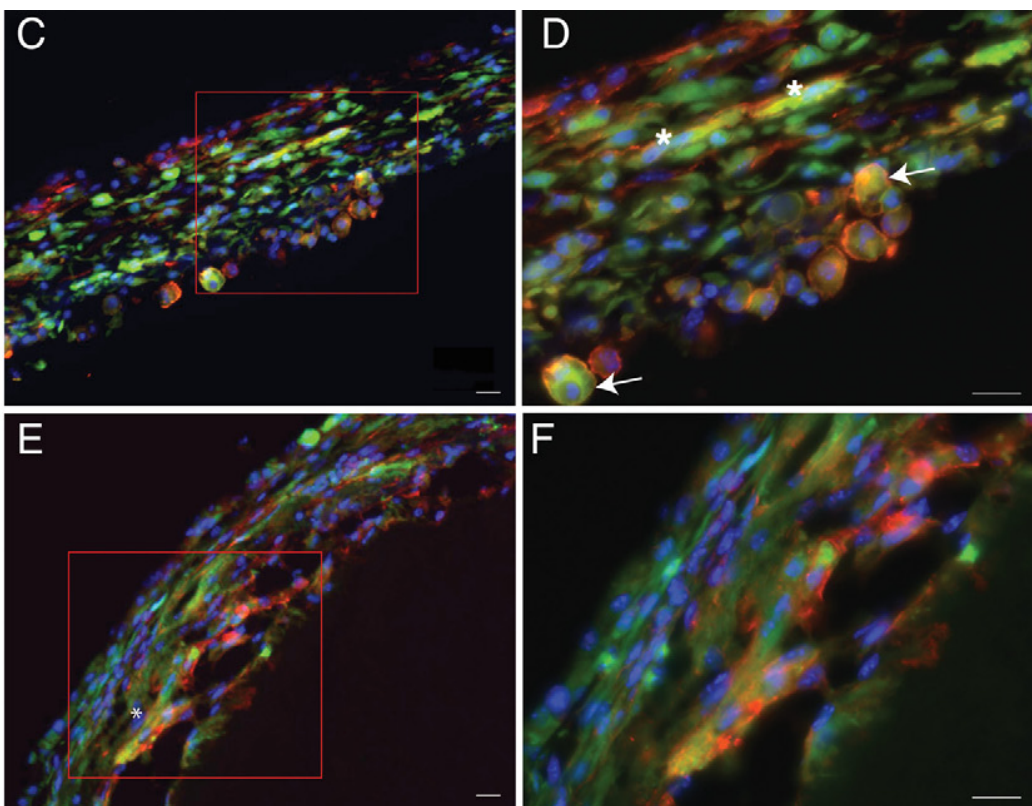

Figure 8. Macrophage-to-myofibroblast transdifferentiation within the tissue capsule. A: Histogram shows the proportions of total cells expressing $\alpha$-SM actin (alone or co-expressing EGFP) within the tissue capsule at days 14, 21, and 28. B: Representative FACS profile of $\alpha$-SM actin expression by day 28 tissue capsule cells. C: Photomicrographs show expression of EGFP (green) and $\alpha$-SM actin (red) in day 14 tissue capsules. D: Higher magnification shows cells of rounded morphology (arrows) and elongated cells (asterisk) co-expressing EGFP and $\alpha$-SM actin. E: Many elongated cells co-expressing EGFP and $\alpha$-SM were observed at day 28. F: Higher magnification. Nuclei counterstained with Hoechst 33342 (blue). Scale bars $=20 \mu \mathrm{m}$. Representative images are from $n=6$ mice for each time point, from two independent experiments.

$>80 \%$ of these cells co-expressing EGFP (Figures 8, A and $\mathrm{B}$ ).

The presence of cells within the tissue capsule that co-express EGFP and $\alpha$-SM actin was confirmed by immunohistochemical analysis. Within the day 14 tissue capsule, the majority of cells co-expressing EGFP and $\alpha$-SM actin exhibited the rounded morphology of macrophages, with a small proportion exhibiting an elongated morphology (Figures 8, C and D). By day 28, an increased proportion of cells co-expressing both markers was observed, and the majority of these exhibited a spindle-shaped morphology (Figure 8, E and F). These results support the hypothesis that macrophages within the capsule transdifferentiate into myofibroblasts.

\section{Discussion}

The peritoneal foreign body response has been used by our laboratory to produce tissue suitable for replacement/ repair of damaged smooth muscle organs. This response resembles that described previously for experimental models of induced inflammation and the response to biomaterials in which the physical and chemical properties of the material modulate the precise cellular events. ${ }^{3,29}$ The present study shows that the cellular response to boiled egg white is similar to that previously reported by our laboratory and others for a variety of foreign materials implanted in the peritoneal cavity, including boiled blood clot, ${ }^{30}$ silastic tubing, ${ }^{5,18}$ poly(lactic acid) scaffolds, ${ }^{31}$ and acellular photo-oxidized bovine pericardium patches. ${ }^{32}$ Given that the foreign object remains free-floating within the peritoneal cavity, our experimental model also provides a means by which to study the cells involved in the sterile inflammatory response without contamination by surrounding tissue. The present study confirms the central role of myeloid cells in the production of tissue that encapsulates foreign objects in the peritoneal cavity and further provides definitive evidence that monocyte/macrophages are able to transdifferentiate in vivo to a myofibroblastic phenotype. Although the primary focus of this study was to investigate the involvement of myeloid cells in the peritoneal foreign body response, the presence of nonmyeloid (EGFP-) cells, including lymphocytes, was also observed in tissue capsule development. This finding is in agreement with results of other studies demonstrating the involvement of lymphocytes in the tissue response to foreign materials. ${ }^{33-35}$

We demonstrate that implantation of sterile foreign objects in the peritoneal cavity initiates an inflammatory response in which EGFP ${ }^{+} \mathrm{Gr}^{+}\left(\mathrm{Ly} 6 \mathrm{C}^{+}\right)$monocytes and granulocytes are rapidly recruited to the peritoneal cavity and encapsulate the foreign object. Morphological analysis shows that the $\mathrm{EGFP}^{+} \mathrm{Gr}^{+}\left(\mathrm{Ly}^{+} \mathrm{C}^{+}\right)$cells, which enter the peritoneal cavity and encapsulate the implanted object in the early phase (at day 2), are primarily granulocytes, with monocytes representing only a minor subset. However, many of these cells also express the macrophage-specific F4/80 antigen, suggesting that monocytes and granulocytes may not represent two different lineages but rather different stages of a single lineage. As the inflammatory response progresses, expression of Ly6C by monocytes and granulocytes is down-regulated, with concomitant up-regulation of $\mathrm{F} 4 / 80$ and the csf1r-EGFP transgene such that $\mathrm{F} 4 / 80^{+}$macrophages become the predominant cell type within the 
peritoneal cavity and the tissue capsule. Thus, we propose that at least some of the so-called "short-lived" $\mathrm{Gr}^{+}{ }^{+}$subset may not undergo apoptosis to be replaced by a second wave of newly recruited monocytes but instead transdifferentiate to $\mathrm{F} 4 / 80^{\circ} \mathrm{Gr} 1^{-}$monocytes. Although this hypothesis needs further investigation, it is supported by previous research showing that the csf1rEGFP reporter is also expressed by $\mathrm{Gr}^{+{ }^{+}}$granulocytes in MacGreen mice and that inflammatory neutrophils can express macrophage-specific genes. ${ }^{20}$ In response to an array of cytokines including granulocyte-macrophage colony-stimulating factor, tumor necrosis factor- $\alpha$, and CSF-1, human neutrophils have also been shown to differentiate into macrophages in vitro. ${ }^{36}$ By day 28, mature "resident-like" macrophages (Gr1-EGFPhiF4/ $80^{\text {hi }}$ ) are the predominant cell type within the peritoneal cavity and the tissue capsule, with a smaller subset of Gr1-EGFPlo $44 / 80^{10}$ cells, comprising predominantly monocytes, also present.

The persistence of macrophages within the tissue capsule surrounding the foreign object is a key feature of the inflammatory response to implanted materials. ${ }^{29}$ In our experimental model, the $\mathrm{EGFP}^{+}$subsets of the day 28 tissue capsule include macrophages, multinucleated giant cells, and a small number of neutrophils, although many cells with spindle-shaped myofibroblastic morphology are also present. The importance of macrophages in capsule development was confirmed by clodronate-encapsulated liposome-mediated depletion experiments, which almost completely abrogated tissue capsule development. In this study, we showed that intraperitoneal injections of clodronate-encapsulated liposomes eliminated both resident peritoneal macrophages and recently recruited monocytes. Not surprisingly, this treatment also almost completely removed the EGFPlo subset, which is composed of predominantly polymorphonuclear neutrophils that also have phagocytic capabilities. It is important to note that this route of administration has been shown to deplete macrophages in spleen, lymph nodes, and liver. ${ }^{23}$ These results indicate that macrophages are essential for development of the multilayered tissue capsule suitable for replacement/repair of smooth muscle organs. ${ }^{5}$

As a central finding, we show that from day 14 onward the developing tissue capsule contains a subset of $\mathrm{EGFP}^{+}$cells that co-express $\alpha$-SM actin, increasing with time to comprise $>80 \%$ of total $\alpha$-SM actin ${ }^{+}$cells within the capsule at day 28. In addition, with progressive development of the tissue capsule the morphology of $\mathrm{EGFP}^{+} \alpha$-SM actin ${ }^{+}$cells changed from a rounded macrophage-like appearance to a more spindle-shaped myofibroblastic phenotype. Taken together, these results provide definitive evidence that monocyte/macrophages are capable of transdifferentiating to myofibroblasts. The retention of EGFP expression by these "transdifferentiated" myofibroblasts is most likely due to the relatively long half-life of the EGFP protein. These results confirm earlier electron microscopic studies, which reported the presence of cells intermediate in morphology between macrophage and fibroblast/myofibroblast within the tissue capsule $^{30}$ and provide evidence that the hematopoietic progenitor of the myofibroblast is the macrophage. ${ }^{4}$

Macrophages have many trophic roles in development and are essential for effective tissue regeneration. ${ }^{37} \mathrm{Al}-$ though the role of macrophages was previously attributed to the paracrine production of cytokine/growth factors and extracellular matrix proteins to recruit and support other cell types, ${ }^{2,38}$ the present study provides evidence for a more direct role in this process by way of their capacity to transdifferentiate into myofibroblasts. The ability of macrophages to transdifferentiate to fibroblasts has been documented previously, ${ }^{39,40}$ with cultured peritoneal macrophages from Schistosoma mansoni chronically infected mice exhibiting fibroblast-like characteristics and co-expressing the fibroblast (procollagen) and macrophage (mac-1/mac-2) markers. Thioglycollatestimulated peritoneum-derived macrophages have also been shown to transdifferentiate into smooth muscle-like cells/myofibroblasts in response to transforming growth factor- $\beta$, evidenced by up-regulation of smooth muscle/ myofibroblast markers such as calponin and $\alpha$-SM actin and concomitant down-regulation of the macrophage marker CD11b. ${ }^{41}$ The bidirectionality of macrophagemyofibroblast-smooth muscle cell transdifferentiation of these two cell types is suggested by the demonstration that smooth muscle cells adopt a macrophage-like phenotype after in vitro cholesterol loading. ${ }^{42}$

The possibility that peritoneal macrophages participating in the peritoneal foreign body response have the capacity to transdifferentiate was first proposed in 1972 by Kouri and Ancheta, ${ }^{43}$ who demonstrated the presence of cells with intermediate morphologies between macrophages and fibroblasts within tissue capsules that formed around Epon lamina implants. Likewise our laboratory identified macrophage-fibroblast intermediary cells in the tissue capsule around free-floating intraperitoneal blood clots, lending further support to the transdifferentiation capacity of peritoneal macrophages..$^{30,44}$ More recently, Jabs et $\mathrm{al}^{18}$ showed that PKH-26-labeled peripheral blood mononuclear cells injected into recipient animals before foreign object implantation incorporated into the tissue capsule and that from day 14 onward, a proportion of $\alpha$-SM actin-expressing spindle-shaped cells co-expressed macrophage markers (ED1/ED2). The present study corroborates and extends these in vivo studies and demonstrates that inflammatory tissue macrophages are capable of acquiring the characteristics of myofibroblasts, including the expression of $\alpha$-SM actin.

These findings indicate a greater cellular plasticity for myeloid cells than previously envisaged and suggest that within its lifetime, a single cell has the capacity to adopt a range of phenotypes and functions according to physiological needs. The results presented here suggest a continuum from monocyte (or granulocyte) through macrophage to myofibroblast. Indeed our previous studies indicate that when subjected to the appropriate environmental cues, such as hemodynamic factors and active stretch, ${ }^{45}$ these cells have the capacity to differentiate even further. For example, when tubes of this myofibroblast-rich tissue (formed around a tubular molding im- 
planted into the peritoneal cavity for 2 to 3 weeks) are grafted into an autologous artery to replace excised segments, the tissue develops the characteristics of mature vascular smooth muscle and constituent cells express smooth muscle differentiation markers including smoothelin and the smooth muscle myosin isoform SM-2. ${ }^{6,7}$

We present here a thorough cellular characterization of the myeloid cells involved in the inflammatory response to implanted foreign material. Specifically, we show that after the initial recruitment of monocytes and granulocytes, macrophages become the predominant cell within both the peritoneal cavity and the tissue capsule. Furthermore, the results provide evidence to suggest that in addition to the established monocyte-to-macrophage differentiation, there is a continuous pathway of maturation from granulocyte through monocyte/macrophage and further to myofibroblast. These results question the traditional notion of distinct terminally differentiated cell types with specific functions. We propose that, at least for some cell lineages, cellular identity is more fluid than recognized previously and that cells may adapt their phenotype and function according to local environmental cues. Understanding the mechanisms regulating this process may be the key to advances in tissue engineering.

\section{Acknowledgments}

We thank Al Dyne for technical assistance and advice on preparation of the figures, Virginia Nink, Janelle Scown, and John Wilson from the Flow Cytometry Facility, Queensland Brain Institute for flow cytometry and cell sorting, and Paul Addison, Tina Chua, and Anthony Chan for histology support.

\section{References}

1. Tang L, Eaton JW: Inflammatory responses to biomaterials. Am J Clin Pathol 1995, 103:466-471

2. Luttikhuizen DT, Harmsen MC, Van Luyn MJ: Cellular and molecular dynamics in the foreign body reaction. Tissue Eng 2006, 12:1955-1970

3. Anderson JM, Rodriguez A, Chang DT: Foreign body reaction to biomaterials. Semin Immunol 2008, 20:86-100

4. Campbell JH, Efendy JL, Han CL, Girjes AA, Campbell GR: Haemopoietic origin of myofibroblasts formed in the peritoneal cavity in response to a foreign body. J Vasc Res 2000, 37:364-371

5. Campbell JH, Efendy JL, Campbell GR: Novel vascular graft grown within recipient's own peritoneal cavity. Circ Res 1999, 85:1173-1178

6. Chue WL, Campbell GR, Caplice N, Muhammed A, Berry CL, Thomas AC, Bennett MB, Campbell JH: Dog peritoneal and pleural cavities as bioreactors to grow autologous vascular grafts. J Vasc Surg 2004, 39:859-867

7. Campbell GR, Turnbull G, Xiang L, Haines M, Armstrong S, Rolfe BE, Campbell $\mathrm{JH}$ : The peritoneal cavity as a bioreactor for tissue engineering visceral organs: bladder, uterus and vas deferens. J Tissue Eng Regen Med 2008, 2:50-60

8. Campbell JH, Efendy JL, Han CL, Campbell GR: Blood vessels from bone marrow. Ann NY Acad Sci 2000, 902:224-229

9. van Furth R, Cohn ZA, Hirsch JG, Humphrey JH, Spector WG, Langevoort HL: The mononuclear phagocyte system: a new classification of macrophages, monocytes, and their precursor cells. Bull World Health Organ 1972, 46:845-852

10. Hume DA: Differentiation and heterogeneity in the mononuclear phagocyte system. Mucosal Immunol 2008, 1:432-441
11. Hume DA: Macrophages as APC and the dendritic cell myth. J Immunol 2008, 181:5829-5835

12. Austyn JM, Gordon S: F4/80, a monoclonal antibody directed specifically against the mouse macrophage. Eur J Immunol 1981, 11: 805-815

13. Khazen W, M'Bika JP, Tomkiewicz C, Benelli C, Chany C, Achour A, Forest $\mathrm{C}$ : Expression of macrophage-selective markers in human and rodent adipocytes. FEBS Lett 2005, 579:5631-5634

14. Hume DA: The mononuclear phagocyte system. Curr Opin Immunol 2006, 18:49-53

15. Geissmann F, Jung S, Littman DR: Blood monocytes consist of two principal subsets with distinct migratory properties. Immunity 2003, 19:71-82

16. Geissmann F, Auffray C, Palframan R, Wirrig C, Ciocca A, Campisi L Narni-Mancinelli E, Lauvau G: Blood monocytes: distinct subsets, how they relate to dendritic cells, and their possible roles in the regulation of T-cell responses. Immunol Cell Biol 2008, 86:398-408

17. Sunderkötter C, Nikolic T, Dillon MJ, Van Rooijen N, Stehling M, Drevets DA, Leenen PJ: Subpopulations of mouse blood monocytes differ in maturation stage and inflammatory response. J Immunol 2004, 172:4410-4417

18. Jabs A, Moncado GA, Nichols CE, Waller EK, Wilcox JN: Peripheral blood mononuclear cells acquire myofibroblast characteristics in granulation tissue. J Vasc Res 2005, 42:174-180

19. Sasmono RT, Oceandy D, Pollard JW, Tong W, Pavli P, Wainwright BJ, Ostrowski MC, Himes SR, Hume DA: A macrophage colonystimulating factor receptor-green fluorescent protein transgene is expressed throughout the mononuclear phagocyte system of the mouse. Blood 2003, 101:1155-1163

20. Sasmono RT, Ehrnsperger A, Cronau SL, Ravasi T, Kandane R, Hickey MJ, Cook AD, Himes SR, Hamilton JA, Hume DA: Mouse neutrophilic granulocytes express mRNA encoding the macrophage colony-stimulating factor receptor (CSF-1R) as well as many other macrophagespecific transcripts and can transdifferentiate into macrophages in vitro in response to CSF-1. J Leukoc Biol 2007, 82:111-123

21. Van Rooijen N, Sanders A: Liposome mediated depletion of macrophages: mechanism of action, preparation of liposomes and applications. J Immunol Methods 1994, 174:83-93

22. van Rooijen N, Sanders A, van den Berg TK: Apoptosis of macrophages induced by liposome-mediated intracellular delivery of clodronate and propamidine. J Immunol Methods 1996, 193:93-99

23. Biewenga J, van der Ende MB, Krist LF, Borst A, Ghufron M, van Rooijen N: Macrophage depletion in the rat after intraperitoneal administration of liposome-encapsulated clodronate: depletion kinetics and accelerated repopulation of peritoneal and omental macrophages by administration of Freund's adjuvant. Cell Tissue Res 1995, 280:189-196

24. Hirschowitz SL, Mandell D, Nieberg RK, Carson K: The alcohol-fixed Diff-Quik stain. A novel rapid stain for the immediate interpretation of fine needle aspiration specimens Acta Cytol 1994, 38:499-501

25. Springer T, Galfre G, Secher DS, Milstein C: Mac-1: a macrophage differentiation antigen identified by monoclonal antibody. Eur J Immunol 1979, 9:301-306

26. Lagasse E, Weissman IL: Flow cytometric identification of murine neutrophils and monocytes. J Immunol Methods 1996, 197:139-150

27. Fleming TJ, Fleming ML, Malek TR: Selective expression of Ly-6G on myeloid lineage cells in mouse bone marrow. RB6-8C5 mAb to granulocyte-differentiation antigen (Gr-1) detects members of the Ly- 6 family J Immunol 1993, 151:2399-2408

28. Biermann H, Pietz B, Dreier R, Schmid KW, Sorg C, Sunderkotter C: Murine leukocytes with ring-shaped nuclei include granulocytes, monocytes, and their precursors. J Leukoc Biol 1999, 65:217-231

29. Anderson JM: Inflammatory response to implants. ASAIO Trans 1988 34:101-107

30. Campbell GR, Ryan GB: Origin of myofibroblasts in the avascular capsule around free-floating intraperitoneal blood-clots. Pathology 1983, 15:253-264

31. Cao Y, Zhang B, Croll T, Rolfe BE, Campbell JH, Campbell GR, Martin $D$, Cooper-White JJ: Engineering tissue tubes using novel multilayered scaffolds in the rat peritoneal cavity. J Biomed Mater Res A 2008, 87:717-727

32. Vranken I, De Visscher G, Lebacq A, Verbeken E, Flameng W: The recruitment of primitive $\mathrm{Lin}^{-} \mathrm{Sca}-1^{+} . \mathrm{CD} 34^{+}, \mathrm{c}-\mathrm{kit}^{+}$and $\mathrm{CD} 271^{+}$cells 
during the early intraperitoneal foreign body reaction Biomaterials 2008, 29:797-808

33. Brodbeck WG, Macewan M, Colton E, Meyerson H, Anderson JM: Lymphocytes and the foreign body response: lymphocyte enhancement of macrophage adhesion and fusion. J Biomed Mater Res A 2005, 74:222-229

34. MacEwan MR, Brodbeck WG, Matsuda T, Anderson JM: Student Research Award in the Undergraduate Degree Candidate category, 30th Annual Meeting of the Society for Biomaterials, Memphis, Tennessee, April 27-30, 2005. Monocyte/lymphocyte interactions and the foreign body response: in vitro effects of biomaterial surface chemistry. J Biomed Mater Res A 2005, 74:285-293

35. Robitaille R, Dusseault J, Henley N, Desbiens K, Labrecque N, Halle JP: Inflammatory response to peritoneal implantation of alginate-polyL-lysine microcapsules. Biomaterials 2005, 26:4119-4127

36. Araki H, Katayama N, Yamashita Y, Mano H, Fujieda A, Usui E, Mitani H, Ohishi K, Nishii K, Masuya M, Minami N, Nobori T, Shiku H: Reprogramming of human postmitotic neutrophils into macrophages by growth factors. Blood 2004, 103:2973-2980

37. Pollard JW: Trophic macrophages in development and disease. Nat Rev Immunol 2009, 9:259-270

38. Gretzer C, Emanuelsson L, Liljensten E, Thomsen P: The inflammatory cell influx and cytokines changes during transition from acute inflam- mation to fibrous repair around implanted materials. J Biomater Sci Polym Ed 2006, 17:669-687

39. Godoy M, Geuskens M, Vanmarck EAE, Borojevic R, Vangansen P. Schistosomiasis and in vitro transdifferentiation of murine peritonealmacrophages into fibroblastic cells. Parasitol Res 1989, 76:150-161

40. Bertrand S, Godoy M, Semal P, Van Gansen P: Transdifferentiation of macrophages into fibroblasts as a result of Schistosoma mansoni infection. Int J Dev Biol 1992, 36:179-184

41. Ninomiya K, Takahashi A, Fujioka Y, Ishikawa Y, Yokoyama M: Transforming growth factor- $\beta$ signaling enhances transdifferentiation of macrophages into smooth muscle-like cells. Hypertens Res 2006, 29:269-276

42. Rong JX, Shapiro M, Trogan E, Fisher EA: Transdifferentiation of mouse aortic smooth muscle cells to a macrophage-like state after cholesterol loading. Proc Natl Acad Sci USA 2003, 100:13531-13536

43. Kouri J, Ancheta O: Transformation of macrophages into fibroblasts. Exp Cell Res 1972, 71:168-176

44. Mosse PRL, Campbell GR, Ryan GB: A comparison of the avascular capsule surrounding free floating intraperitoneal blood-clots in mice and rabbits. Pathology 1985, 17:401-407

45. Efendy JL, Campbell GR, Campbell JH: The effect of environmental cues on the differentiation of myofibroblasts in peritoneal granulation tissue. J Pathol 2000, 192:257-262 